\title{
SHOTCRETE ROBOT FOR IMPROVING WORKING CONDITIONS, QUALITY AND ECONOMY IN CIVIL ENGINEERING AND TUNNELLING
}

\author{
O. PROF. DR.-ING. B. MAIDL \\ DEPARTMENT OF BUILDING TECHNOLOGY, TUNNELLING AND \\ CONSTRUCTION MANAGEMENT \\ RUHR-UNIVERSITY BOCHUM
}

UNIVERSIT ÄTSSTR. 150

4630 BOCHUM, GERMANY

\section{SUMMARY}

The construction material, shotcrete, has gained more importance in the last years, more especially in tunnelling and underground construction. Through the automation of the shotcrete nozzle control by means of a shotcrete robot, the deficiencies in shotcreting with respect to the assessment criteria of concrete quality, economy (rebound) and working conditions (dust development) which occur during the conventional manual treatment could be nearly eliminated. The important fundamentals for the automation of the nozzle control is an optimal nozzle control technology. This is an up to date report on existing research works at the department of Building Technology, Tunnelling and Construction Management, University of Bochum, as well as the practical application of the research results with the converted industrial robot Unimate $2105 \mathrm{G}$ in the research mine Tremonia in Dortmund and also the further planned research activities.

\section{INTRODUCTION}

There has been a steady increase in the application of the construction material shotcrete in the last years.

The fields of application are very manifold, ranging from the creation of new openings in mines, trench protection and excavation support in underground construction, to the always increasing and more important rehabilitation measures. The largest support given to the application of shotcrete is, however, experienced in modern tunnelling where the driving of underground openings is even hardly imaginable without shotcrete application due to the fast development of the shotcrete method of construction. This development was not only forced by the construction of tion. This development was not on networks that required a route selection with intensified efforts in rerouting underground and surface rail traffic networks in the cities. About $90 \%$ of these tunnel construction works are presently built of shotcrete. The important tunnelling technological properties of this construction material lie in its load-bearing behaviour and its flexibility of application [1].

The numerous advantages offered by the construction material shotcrete should however not obscure the fact that there are problems associated with its application. Firstly to be named are the partially unacceptable working conditions in the form of high dust development, rebound material flying about and crumbling away stones which enormously affect the nozzle-man. But there are 
also many shortcomings with regards to the rebound material portions as well as a uniform material quality, which both depend Decisive nozzle-man.

in shotcreting can be improvements in respect of the named deficiencies nozzle control. The nozzle-mad through the automation shotcrete dangerous working area and carry could thus be removed from the are assigned to him in a control out the supervisory duties which equally important advantage of plant from a safer distance. An has so far been underrated lies an automatic nozzle control that optimal in the exact reproductivity of an conditions control technology, also under difficult working conditions. Remarkable material quality uniformity can be achieved as well as a reduction in rebound [2], [3].

The following is a brief report on the up to date research works of the Department of Building Technology, Tunnelling and Construction Management, University of Bochum, in cooperation with the Secretary of Research and Technology (FRG), the STUVA Köln, the Employers' Liability Insurance Association for Foundation Engineering (Tiefbau-Berufsgenossenschaft) Munich, the Mining Professional Association (Bergbau-Berufsgenossenschaft), some building machinery producers and building contractors, as automation.
autanned efforts in the shotcrete nozzle control

\section{SHOTCRETE TEST PLANT AT THE RUHR-UNIVERSITY BOCHUM}

After the indication in the mid.-80's that no remarkable improvements with respect to the assessment criteria for the shotcrete production, concrete quality, rebound and dust development could be effected through modifications of the production process and machinery technology, an automation of the shotcrete nozzle control was aimed at.

By these
works, special
emphases were
laid on the
developments

that were not

only purely

pragmatically

carried out. Ra-

ther, all the

essential fundamentals should

be compiled to be able to make an optimal use of the advantages of an automatic nozzle control. As the most important research point is to be crystallized in an elaborated opti-

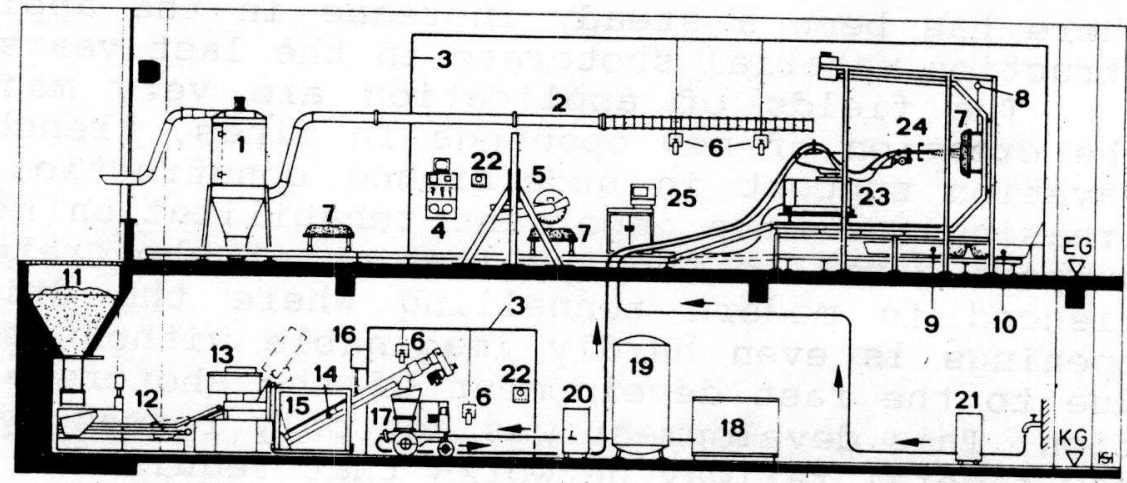

1. dust extraction unit 2. ventilation system

3. dustproof enclosure

4. data measurement \& recording

5. drill and cutting rig

6. dust measuring equipment

7. movable testing area

8. palette scale

9. rebound scale

10. lost - material - tub

11. storage: aggregate, cement

12. dosage: aggregate, cement

13. force mixer
14. dosage screw conveyer

15. storage silo, scale

16. addition of setting accelerator

17. shotcrete machine

18. compressor

19. air tank

20. measuring and control unit (air)

21. measuring and control unit (water)

22. intercom system

23. shotcrete robot

24. distance measuring device

25. control unit of shotcrete robot

Fig.1: Shotcrete test plant at the RuhrUniversity Bochum

mal nozzle control technology. 
Ideal requirements are offered by the shotcrete research plant at the Ruhr-University in Bochum. Within the framework of these tests of the processing and concrete technological influences on shotcrete production, this shotcrete test plant was constructed at the Department of Building Technology, Tunnelling and Construction Management with the basic idea of creating the possibility of carrying out identical repetitive tests and also producing a quality shotcrete under specified and constant conditions. This is the only way of ensuring the possibility of the essential statistical analyses of the tests carried out and those planned. A systematic description of the shotcrete test plant as well as its technical installations and equipment are shown in fig. 1 .

Since shotcrete production is a continuous process, the parameters influencing the processing technology have to be kept time constant. Special importance need to be dedicated to the parameters "conveyance of the initial mix" as well as "addition of water","addition of air volume" and "addition of setting accelerators".

On the
shotcrete test
plant, these
quantities are
electronically
regulated and
recorded by a
control and mo-
nitoring system
so that constant
conditions are
maintained du-
ring the entire
shotcrete pro-
duction process.
In addition, all
the necessary
equipment for
the technical
recording of the
concrete qua-
lity, rebound

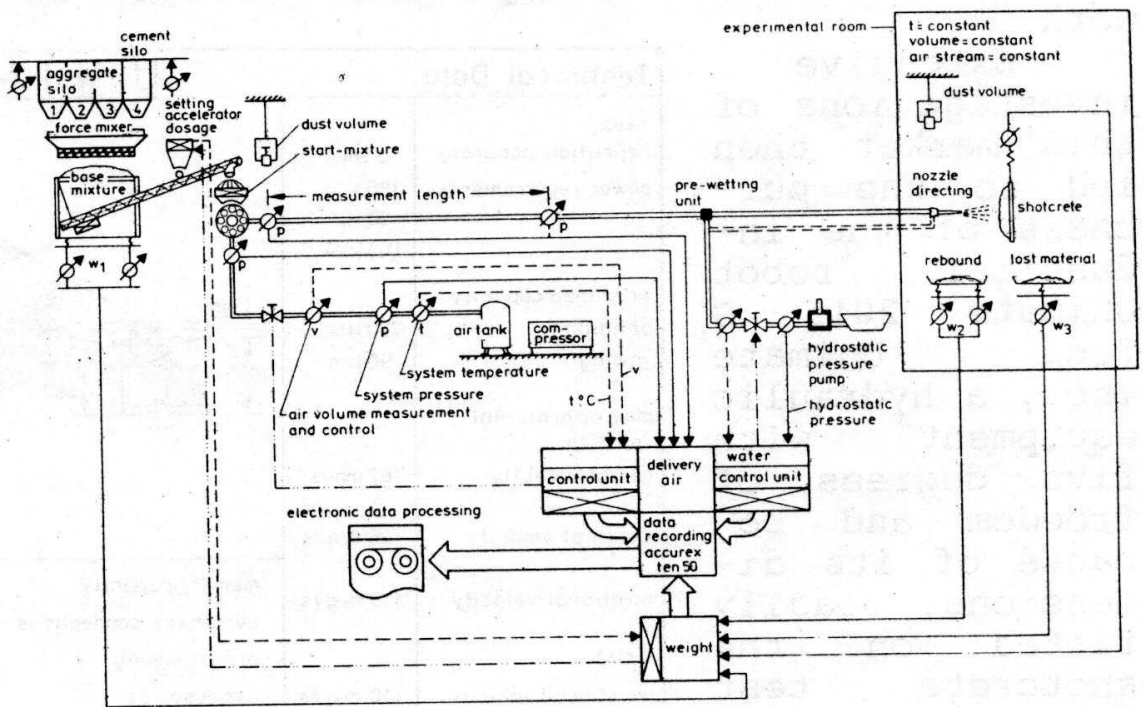

$\triangle$ meosuring and

Fig. 2: Measurement, checking and control functions on the shotcrete test plant

and dust concentration are available.

The integrated drill and cutting rig as well as the numerous test equipment offer the possibility of concrete technological control through the adequate fresh and hardened concrete tests.

The shotcrete quality will be ascertained by the compressive strength, its dispersion, as well as the uniformity of the shotcrete.

For the compressive strength tests, the shotcrete test specimen core sample could be removed and tested in compression after storage in accordance with DIN 1048. The scatter of the compressive strength, a measure of the material grade consistency, is obtained after a statistical analyses of the compressive strength data and adjustment of outliers as coefficient of variation the compressive strength test values. The test of uniformity is performed with shotcrete discs that are sawn from the test specimen for this purpose and with the assistance of computers analysed in regard of their grain size distribution. 
The rebound portion will be determined by a continuous weight recording of the initial shotcrete quantity, the applied shotcrete as well as the rebound quantity collected in a trough.

Dust measurements could be carried out with gravimetric dust gauges of type VC $25 \mathrm{~F}$ which are installed at a defined distance from the sprayed surface in the nozzle area.

The large quantity of data resulting from the monitoring are conveyed to a data acquisition equipment and transmitted to the department's own computers for further analysis.

For the carrying out of the basic tests with respect to the nozzle control technology, an appropriate nozzle control system was integrated on the test plant with which the different movement directions on the test plant should be simulated.

First considerations were limited to self-constructions which, however, were immediately rejected; for it turned out that the robot market offers solutions to the problem in question that are based on developed and frequently tried technology and could thus save us from the expensive and time intensive developmental work.

\section{Extensive}

investigations of this market then led to the purchase of the industrial robot Unimate $2015 \quad \mathrm{G}$ from Unimate Inc., a hydraulic equipment with five degrees of freedom and because of its dimensions, readily fitted on the shotcrete test plant.

The working area as well as the comfortable VAL II-Control, which guarantee an unlimited number of tests as well as also the possibility to try these equipment on building sites, were the important arguments for the decision in favour of this equipment. A sketch of Unimate $2105 \mathrm{G}$ as well as the important technical data are shown in fig. 3 .

To the simulation of the nozzle self movement which should be comparatively considered in the framework of the fundamental tests, a separate nozzle self drive was

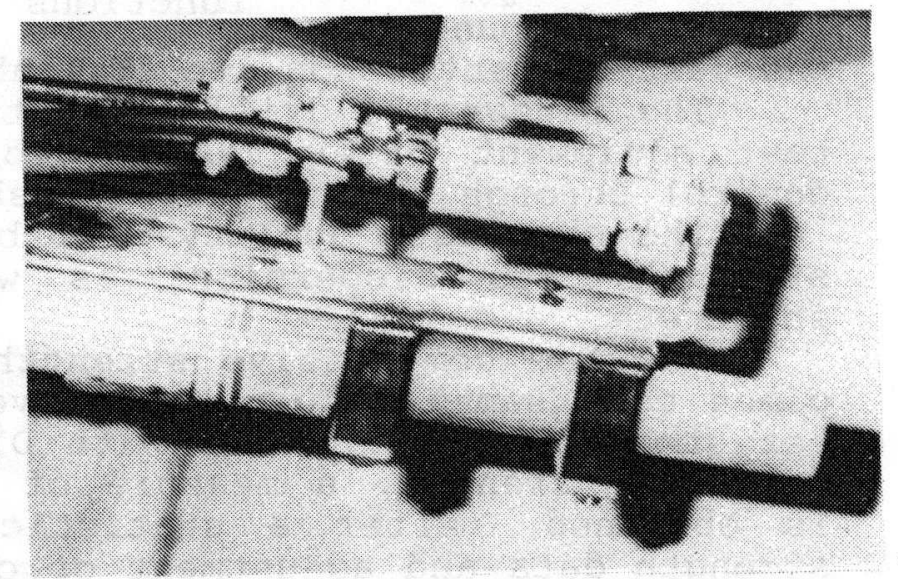

Fig.4: Nozzle self drive constructed. This hydraulically operated supplementary drive is fixed to the arm hinge and permits turn and swing motions of the 
nozzle with variable radii and frequencies. The radii and the amplitudes are respectively selectable from movable eccentric discs gradually from 0 to $70 \mathrm{~cm}$ on the spray surface. The separate hydraulic unit permits rotational speeds between 0 and $400 \mathrm{rpm}$.

After the conversion of the robot and the, integration of the equipment on the test plant, a series of tests could then be carried out, thereby technically trying the equipment and followed with an intensive robot control training. Furthermore, nozzle control programs were developed in which the appropriate motion controls were programmed.

The nozzle control programs permit variations of the directions of motion which were adapted to the test area and at the same time guarantee a uniformity of the test specimen.

The robot is therefore in a position to repeat at random every nozzle control with extreme higher speed, thus fulfilling the decisive requirements for comparative nozzle control tests.

\section{TEST RESULTS OF THE INFLUENCE OF NOZZLE CONTROL ON SHOTCRETING}

After the installation of the required testing equipment, about 60 tests in scale $1: 1$ were carried out to investigate the nozzle control influences on the important assessment criteria of shotcrete production, concrete quality, rebound and dust development [4].

To work on a specific test program, the nozzle motion control must first be broken down into single components and then through variation of the single parameter, determine the possible influences. By the parameter variations, the findings from interviewing several "nozzlemen" as well as video recordings of manual nozzle control were adopted.

Besides, variations outside these ranges were intentionally selected in order to determine if, for example, nozzle control techniques have a positive influence on shotcreting which a "nozzle-man" can not solely physically carry out (for example high frequency circular motions by faster nozzle control motion).

The aim of this test is that, for the single nozzle control parameter, an optimum is determined in respect of concrete quality criteria, economy and working conditions to be able to give specifications for an ideal nozzle control technology.

The tests carried out led to the conclusion that nozzle control in shotcreting is of greater importance than previously attached. Thus, remarkable improvements can be achieved in respect of rebound, dust development and shotcrete quality by a suitable choice of the nozzle control parameters, especially by a large dynamic of the nozzle self movement. 
Examplary list in fig. 6 are the results of the influence of the nozzle self movement on rebound, dust development and uniformity of concrete. Considering the adverse working conditions which were revealed by the tests of the nozzle control technology, the requirements of a nozzle-man by manual nozzle control can not cast during a long run. Only the application of an automatic nozzle control system can always guarantee an optimal nozzle control in shotcreting and also lighten the work of the nozzle-man, which will be a supervisory function from a safer distance.

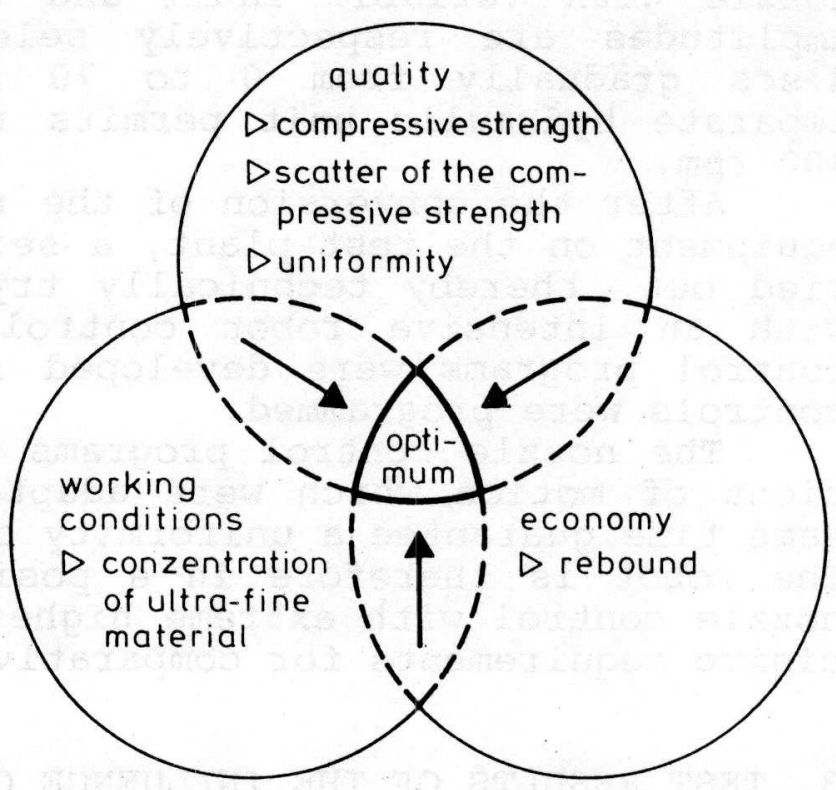

Fig.5: Optimation range for the nozzle control parameters.
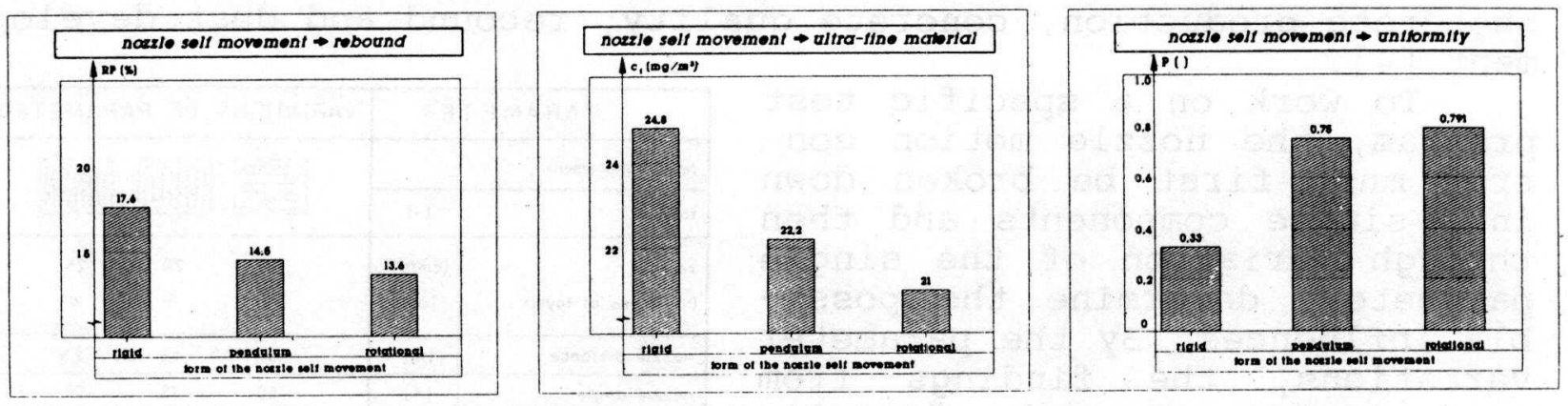

Fig.6: Rebound, dust development and concrete uniformity in relationship to form of nozzle self movement

\section{TRIAL OF DISTANCE MEASURING INSTRUMENTS}

Whilst the form of nozzle control motion and its speed as well as the form and frequency of the nozzle self movement are realised through appropriate programming of the robot control and adjustment of the nozzle self drive, an integration of the corresponding sensors in the control is desirable for the flexible regulation of the nozzle range and nozzle angle.

Some essential preparatory works on this complex theme have already been carried out with the systematic trial distance gauging device on the shotcrete test plant [5].

It is necessary to find special robust sensors which function perfectly under extreme surroundings prevailing by shotcreting. As externally disturbing influences to be named are dust development, poor light, visibility and contrast relationships, moist surrounding air, rough reflecting surfaces, rebound material flying around and dynamic loads from the nozzle vibrations. 
Preceding theoretical studies led to the knowledge that noncontact distance gauging under these conditions based on ultrasonic measurements or on distance gauging with laser beams or microwaves can be considered. After an intensive search on this market as well as several technical consultations with producers, 14 available instruments were tested.

The instruments were driven parallel to the nozzle at a distance of about $40 \mathrm{~cm}$ with the help of a special support construction. At an edge of the test area, there was a gap with which additional openings were simulated.

The measured distance data were transmitted to a recorder and to a computer.

Peculiar to the ultrasonic and radar measurements is the conical or lobar enlargement of the waves in the direction of the target. The measurement is therefore not exact and lead to considerable false measurement of rebound material.

In the case of over-
head shotcreting, these false measurements were so numerous that hardly more useful signals could be recorded.

Whilst a radar instrument can relatively be protected against extreme dirtiness, especially in the over-head shotcreting area, it is totally impossible in the case of ultrasonic measuring devices. The sensor-heads become so dirty within few seconds that no more measurement signals could be sent out.

Additionally, both methods cannot be used for measurements through reinforcing steel mats and angular deflections cause partially remarkable influences of the measurement signals, especially by the radar measuring method.

The tests therefore led to the conclusion that radar and ultrasonic measurement

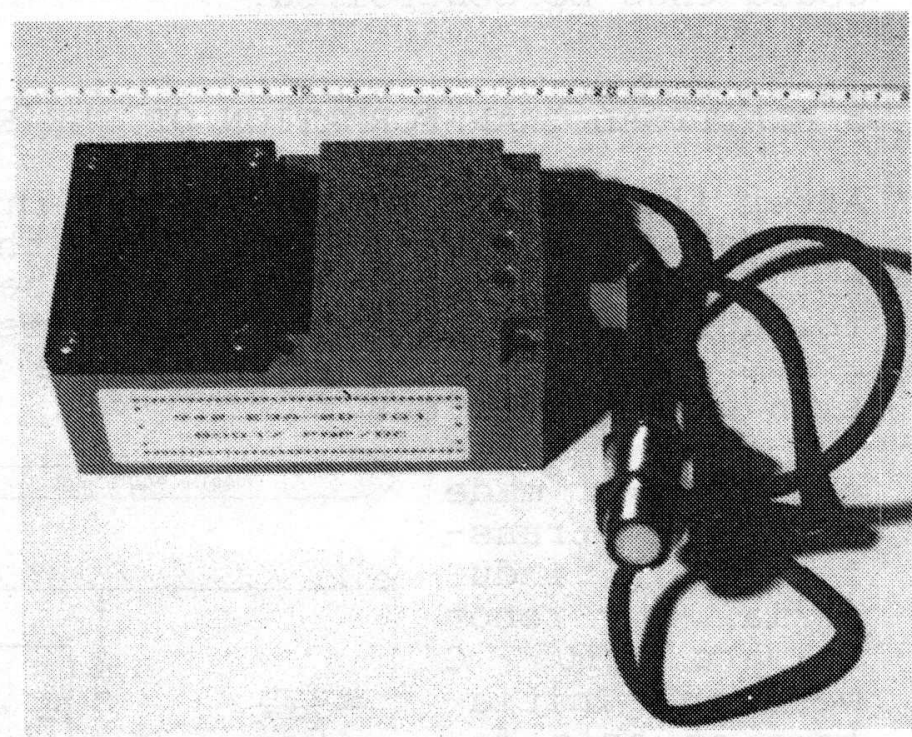

Fig.7: Ultrasonic instrument



Fig.8: Infrared laser methods are unsuitable in this situation for the contactless distance measurements in shotcreting.

The measurement signals of the tested infrared laser, on the contrary, proved not to be influenced by the rebound material. Both the required distance to the shotcrete surface as well as gaps could be recorded very exactly. 
Also, the angular deflections as well as the measurements through concrete reinforcing mats by distance measurements with infrared laser offered no problems.

It is solely by the over-head shotcreting that a relatively fast dirtying of the laser optic occured, which in the end led to loss of signals. However, improvements were realised when a glass plate with provisional compressed air nozzle reception was placed in front of it. With a selected protective device for the laser optic, possibly with compressed air nozzle reception through specially constructed compressed air nozzles, this complex problem could thus be controlled.

\section{PRACTICAL TRANSFORMATION OF THE RESULTS}

After the determination of the influences of the nozzle control technology on shotcreting and the conclusion to automate the nozzle control, there followed the demand for a practical transformation of the obtained test results. It should be proved that a shotcrete robot is also capable to be used under real construction site conditions.

The good

experiences made with the transformed industrial robot Unimate $2105 \quad \mathrm{G}$ were the initiators of this demonstrative test with the available equipment.

For

this

purpose, in $\mathrm{Ja}-$ nuary 1991, the entire installation at the

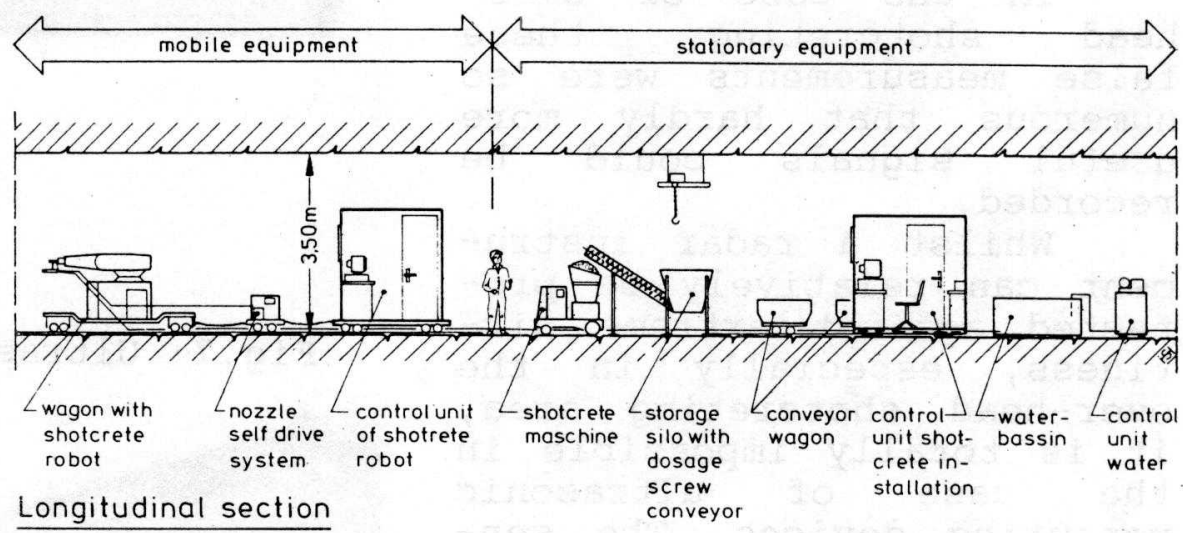

Fig.9: Test set up in the research mine shotcrete test plant was installed at an auxiliary route in the research mine Tremonia in Dortmund.

The shotcrete robot, the nozzle self drive and the control unit of the shotcrete robot were mounted on a special flat loader. This provided the possibility of moving all the essential devices for the nozzle control on a rail system along the tunnel longitudinal axis.

Behind these mobile installations were the stationary equipment comprising of the shotcrete machine with field of activity, the control unit for the

Tremonia in Dortmund

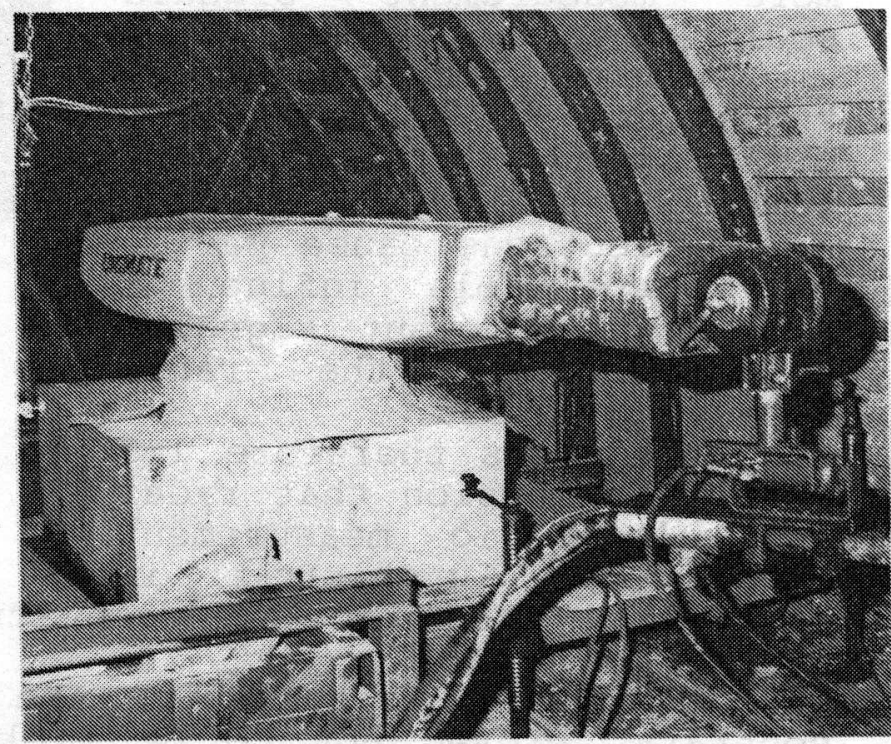

Fig.10: Shotcrete robot at mine Tremonia 
shotcrete installation, as well as the water bassin and the control unit for the water. The control unit of the shotcrete robot and shotcrete device were housed in a dustproof container. The section found to be developed in the research mine demanded an adjustment of the control programmes that were developed from the work at the university test plant. The tunnel of $12,6 \mathrm{~m}^{2}$ large cross-section was secured with arch supports (bell section). As lagging, $15 \mathrm{~cm}$ high concrete slabs placed $15 \mathrm{~cm}$ apart, were arranged across the whole cross-section. In addition, this support was manually backfilled with parts of the underground excavation. Especially, in the areas where the concrete slabs partly have considerable spaces behind them, required high demands were of the program control.

An adaptation of the programm control could, however, be successfully carried out.

The tests carried out at Tremonia especially demonstrated that the application of shotcrete robots is possible under real construction site conditions. During the entire shotcreting process, the requirements obtained at RuhrUniversity of Bochum test plant in respect of the nozzle control and nozzle self movement parameters, could be kept. The positive experiences with regards to improved concrete quality, rebound reduction and dust development reduction through optimization of the nozzle control technology were confirmed.

\section{PROSPECTS}

Despite the successful tests with the industrial robot Unimate $2105 \mathrm{G}$ in the research mine Tremonia in Dortmund, it should not be understood that the equipment used here is a normal, but purposely for the demonstration of the many advantages of automatic shotcreting, converted robot. The development of a specified shotcrete robot is still overdue.

The experiences from the practical application show that improvements are necessary in the kinematic efficiencies, adaptation of the geometrical dimensions and a further robot control flexibility of a future equipment is also wished.

A further important and essential research point is devoted to the integration of the shotcrete robot in the construction technology. The operations involved in cavern constructions can be changed only under strong observation of the time dependent relationship between the ground deformations and the introduction of supportive measures. The tunnelling technology is therefore to be investigated under the consideration of the changing relationships between robots and construction methods and be modified in the necessary situations in respect of the integration of the new equipment components. 
The most important aspects of the tests carried out show that some amount of work need to be done before the construction of the first, marketable shotcreting robot. The interdisciplinary problem demands an extensive cooperation with other scientific disciplines. Especially the control technological problems require the fusion of know-how from the automation engineering discipline. The designing of a new working area for the nozzleman (installation and control of system), as well as the required personnel retraining measures as a result of the new technology make the cooperation with other scientific researchers unavoidable. First considerations made in the organisation and financing of this interdisciplinary research project already exist.

It is hoped that the solution of the above mentioned problems could soon lead to the availability of a marketable shotcrete robot with the corresponding construction technological knowledge for shotcreting for ensuring the availability, which was proved up to date only with test results in respect of construction material quality, economy and the working conditions that have been obtained under laboratory conditions and the trial tests in the Tremonia research mine to the practical man.

7 REFERENCES

1 Maidl, B.: Handbuch des Tunnel- und Stollenbaus, Band I: Konstruktionen und Verfahren, Essen: Verlag Glückauf 1984

2 Maidl, B.: Handbuch für Stahlfaserspritzbeton, Berlin: Verlag Ernst \& Sohn 1991 (in Vorbereitung)

3 Maidl, B.: Handbuch für Spritzbeton, Berlin: Verlag Ernst \& Sohn 1991 (in Vorbereitung)

4 Guthoff, K.: Untersuchungen zum Einfluß der Düsenführung auf die Spritzbetonherstellung, Baumaschine und Bautechnik 37 (1990), Heft 1

5 Maidl, B.: Spritzroboter im Tunnelbau, VDI-Berichte 800, 1990 